\title{
The BRAzil MAGnesium (BRAMAG) trial: a randomized clinical trial of oral magnesium supplementation in pregnancy for the prevention of preterm birth and perinatal and maternal morbidity
}

Joao Guilherme B Alves ${ }^{1}$, Carla Adriane Fonseca Leal de Araújo ${ }^{1}$, Isabelle E A Pontes ${ }^{1}$, Angélica C Guimarães ${ }^{2}$ and Joel G Ray ${ }^{3 *}$

\begin{abstract}
Background: Preterm birth is the leading cause of infant mortality globally, including Brazil. We will evaluate whether oral magnesium citrate reduces the risk of placental dysfunction and its negative consequences for both the fetus and mother, which, in turn, should reduce the need for indicated preterm delivery.

Methods/Design: We will complete a multicenter, randomized double-blind clinical trial comparing oral magnesium citrate $150 \mathrm{mg}$ twice daily ( $n=2000$ women) to matched placebo ( $n=1000$ women), starting at $12^{1 / 7}$ to $20^{6 / 7}$ weeks gestation and continued until delivery. We will include women at higher risk for placental dysfunction, based on clinical factors from a prior pregnancy (e.g., prior preterm delivery, stillbirth or preeclampsia) or the current pregnancy (e.g., chronic hypertension, pre-pregnancy diabetes mellitus, maternal age $>35$ years or pre-pregnancy maternal body mass index $>30 \mathrm{~kg} / \mathrm{m}^{2}$ ). The primary perinatal outcome is a composite of preterm birth $<37$ weeks gestation, stillbirth $>20$ weeks gestation, neonatal death $<28$ days, or SGA birthweight $<3$ rd percentile. The primary composite maternal outcome is preeclampsia arising $<37$ weeks gestation, severe non-proteinuric hypertension arising $<37$ weeks gestation, placental abruption, maternal stroke during pregnancy or $\leq 7$ days after delivery, or maternal death during pregnancy or $\leq 7$ days after delivery.
\end{abstract}

Discussion: The results of this randomized clinical trial may be especially relevant in low and middle income countries that have high rates of prematurity and limited resources for acute newborn and maternal care.

Trial registration: ClinicalTrials.gov Identifier NCT02032186, registered December 19, 2013.

Keywords: Magnesium, Pregnancy, Prevention, Preeclampsia, Hypertension, Placenta, Perinatal, Preterm birth, Prematurity, Small for gestational age, Stillbirth

\footnotetext{
* Correspondence: rayj@smh.ca

${ }^{3}$ Departments of Medicine, Obstetrics and Health Policy Management Evaluation, University of Toronto, St. Michael's Hospital, 30 Bond Street, Toronto, ON M5B 1 W8, Canada

Full list of author information is available at the end of the article
} 


\section{Background}

\section{Prematurity as a serious public health problem}

According to the World Health Organization (WHO), 15 million children each year are born preterm before 37 weeks gestation [1]. Prematurity is the leading cause of death in the neonatal period [2,3], and is the second leading cause of death in children aged 5 years and younger [1]. In low income countries, preterm birth before 32 weeks gestation has a mortality rate of $50 \%[1,2]$. Among survivors, serious morbidity arises in the form of cerebral palsy and both visual and hearing impairment $[4,5]$, which negatively impacts on the social and economic productivity of the family unit and the nation at large [6-8]. In the US, $\$ 26$ billion are spent each year for the in-hospital care of the premature infant, a value that does not even include ongoing care and monitoring thereafter [6].

Globally, Brazil is among the top-10 countries with the largest number of premature births [1]. In 2011, among nearly three million births recorded in Brazil, 400,000 (13.6\%) were preterm, contributing to almost half of the 40,000 infant deaths in that year [9].

\section{Prevention of preterm labor - the placenta as a target organ}

The main forms of preterm delivery are either by spontaneous mechanisms (i.e., preterm labor with intact membranes or preterm premature rupture of membranes [PPROM]), or by way of intervention - provider initiated ("medically indicated") preterm delivery" - in response to a maternal condition (e.g., preeclampsia), or a fetal indication (e.g., small for gestational age [SGA] fetal weight) [10]. Provider initiated preterm birth accounts for $41 \%$, followed by spontaneous preterm labor (32\%) and PPROM (27\%) [11]. Among U.S. women whose first pregnancy resulted in a provider initiated preterm birth, there was a much higher subsequent chance of preterm birth by medical indication in the second pregnancy (odds ratio [OR] 10.6, 95\% confidence interval [CI] 10.112.4), but less so if it followed a prior spontaneous preterm birth (OR 1.6, 95\% CI 1.3-2.1) [12].

Two major factors appear to increase neonatal morbidity and mortality in the presence of preterm birth: i) SGA below the expected 10th percentile, and ii) the hypertensive disorders of pregnancy. Both factors especially potentiate the risk in relation to a provider initiated (medically indicated preterm birth).

In the EUROPOP Study, 23\% of preterm infants born at 22 to 36 weeks gestation were SGA (adjusted OR, 2.33, 95\% CI 2.09-2.60) [13]. Moreover, upon restricting their analysis to women with provider-initiated preterm birth, the effect of SGA was even greater (OR 6.38, 95\% CI 5.47-7.45). The latter is especially noteworthy, since preterm interruption of pregnancies is a substantial and growing cause of preterm delivery in Brazil [14]. In the 2004 Pelotas birth cohort, $45 \%$ of Brazilian preterm birth were spontaneous and $55 \%$ were by indicated vaginal induction or Cesarean section [11]. Brazilian neonates delivered at late preterm, and who are also SGA, have higher morbidity than late preterm infants whose weight is appropriate for gestational age [15].

In a population-based study 97,000 live born singleton infants born to nulliparous Swedish women, there was a pronounced association between the hypertensive disease of pregnancy and SGA, especially for preeclampsia resulting in preterm delivery $\leq 32$ weeks (OR of SGA: 40.5, 95\% CI 31.5-51.4) and at 33-36 weeks (OR of SGA: 17.4, 95\% CI 15.7-19.3) [16].

As noted by others, preterm delivery of the SGA fetus is especially pronounced in the co-presence of severe hypertensive disorders of pregnancy [17], of which $66 \%$ of preterm birth are provider initiated [18]. In a study from the Southern Brazil, for example, treated hypertension was associated with an OR of 2.74 (95\% CI 1.784.22) for preterm birth, specifically among low-income mothers [10].

While both SGA and maternal hypertension may necessitate provider-initiated ("indicated") preterm delivery [18-20] it is understood that placental dysfunction may be a major mediator of all three [21], as shown in Figure 1.

Placental dysfunction may result in adverse maternal clinical outcomes, namely, preeclampsia, placental abruption \& placental infarction [22,23], as well as adverse perinatal outcomes, namely, stillbirth, poor fetal growth and preterm birth [24]. In Brazil, the national rate of stillbirths is 9.5 per 1000 births, while the corresponding rate is 27 per 1000 births in Northeast Brazil [25]. A significant percentage of stillbirths are related to nutritional deficiencies, and placental dysfunction is believed to be a cause of many, especially those stillbirths occurring preterm [26].

Placental dysfunction is particularly apparent when preeclampsia and preterm delivery occur concomitantly [27]. Interestingly, $\mathrm{Mg}^{++}$has an immediate effect on placental vascular flow and reduced placental vascular flow is at least, in part, responsible for placental insufficiency and fetal intra-uterus growth restriction [28].

\section{Rationale for a preventive clinical trial of oral $\mathrm{Mg}^{++}$citrate in pregnancy}

We require a preventive strategy that attenuates and/or delays the development of placental dysfunction, and thus, decreases the onset of SGA and/or hypertensive disorders of pregnancy. In turn, this should reduce the need for preterm induction of labor or Cesarean delivery (i.e., provider initiated preterm delivery). Improving placental health should reduce the risk of antepartum and/or intrapartum stillbirth. 


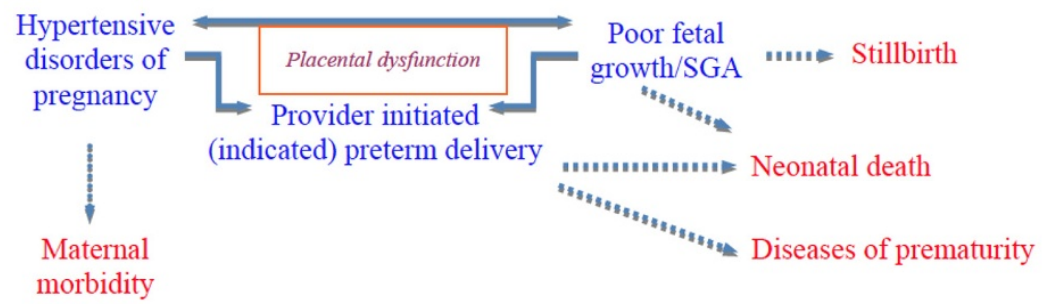

SGA small for gestational age birthweight

Figure 1 Placental dysfunction and its negative consequences for a woman mother and her fetus/newborn.

Although present in grains, green vegetables and seeds, insufficient $\mathrm{Mg}^{++}$intake is common, especially in low-income regions. Adolescents and women are more prone to $\mathrm{Mg}^{++}$deficiency [29]. It is recommended that women consume $280 \mathrm{mg}$ of $\mathrm{Mg}^{++}$per day [30], increasing in pregnancy [31]. Most $\mathrm{Mg}^{++}(99 \%)$ is intra-cellular, such that serum levels have a low accuracy for $\mathrm{Mg}^{++}$ deficiency [32]. Total and ionized $\mathrm{Mg}^{++}$are inversely associated with gestational age in pregnancy [33]. $\mathrm{Mg}^{++}$ deficiency in pregnancy has been associated with a higher risk of chronic hypertension, preeclampsia, placental dysfunction and premature labor [34].

Oral $\mathrm{Mg}^{++}$supplementation has been evaluated in pregnancy in a minor number of randomized controlled trials (RCT) (Table 1). A meta-analysis included seven RCTs, comprising 2,689 pregnant women [35]. In 6 RCTs, women were randomly allocated to an oral $\mathrm{Mg}^{++}$ supplement vs. a control group; the seventh study was a cluster RCT. Starting oral $\mathrm{Mg}^{++}$supplementation before 25 weeks gestation was associated with a lower risk of PTB (RR 0.73, 95\% CI 0.57-0.94). There was a lower risk of SGA (RR 0.70, 95\% CI 0.53 to 0.93), fewer hospitalizations during pregnancy (RR $0.66,95 \%$ CI 0.49 to 0.89 ) and fewer cases of antepartum hemorrhage (RR $0.38,95 \%$ CI 0.16 to 0.90 ) [35]. While $\mathrm{Mg}^{++}$supplementation reduced the risk of preeclampsia by $13 \%$, this effect was not significantly so. However, since preterm onset of preeclampsia or severe preeclampsia was not specifically analyzed in the meta-analysis, few women had that outcome assessed, so little can be deduced about the impact of $\mathrm{Mg}^{++}$supplementation on this relevant outcome. Moreover, it was not clear if the observed $27 \%$ relative risk reduction for preterm birth was predominantly a reduction in spontaneous vs. provider initiated preterm birth.

More recent data suggest that maternal $\mathrm{Mg}^{++}$supplementation in pregnancy may have other perinatal benefits. In a double-blind RCT, 4,494 South African black pregnant women of low socioeconomic status were randomized to receive daily $128 \mathrm{mg} \mathrm{Mg}{ }^{++}$stearate slowrelease or matching placebo [36]. Treatment was begun after 22 weeks gestation in most women, and was sustained for a mean of about 28 days in both groups. The rate of preterm delivery was $11.4 \%$ in the placebo group and $11.7 \%$ in the $\mathrm{Mg}^{++}$group. The risk of the primary outcome of hypoxic-ischemic encephalopathy was nonsignificantly lower in the $\mathrm{Mg}^{++}$group (OR $0.70,95 \%$ CI 0.36 to 1.35 ), but the overall event rate was lower than expected in both groups. Interestingly, the risk of 3rdtrimester stillbirth was lower in $\mathrm{Mg}^{++}$arm (OR 0.32, 95\% CI 0.12 to 0.87 ). The late initiation and limited duration of $\mathrm{Mg}^{++}$supplementation may have limited the evaluation of the efficacy of $\mathrm{Mg}^{++}$in this RCT.

As stated by others, there is not enough high quality evidence to show that $\mathrm{Mg}^{++}$supplementation during pregnancy is beneficial [35]. Certainly, what is needed is an RCT that enrolls enough women at risk, at an early

Table 1 Pooled data from randomized clinical trials of oral magnesium supplementation in pregnancy for the prevention of adverse pregnancy outcomes

\begin{tabular}{lcccc}
\hline Outcome & $\begin{array}{c}\text { Number of participants } \\
\text { (RCTs) included }\end{array}$ & $\begin{array}{c}\text { Control event rate } \\
\text { (per 1000) }\end{array}$ & $\begin{array}{c}\text { Magnesium supplementation } \\
\text { event rate (per 1000) }\end{array}$ & $\begin{array}{c}\text { Relative risk reduction,\% } \\
\text { (95\% confidence interval) }\end{array}$ \\
\hline Preterm birth <37 weeks gestation & $2275(5)$ & 105 & 67 & $27(6$ to 43$)$ \\
Preeclampsia & $474(2)$ & 167 & 145 & $13(-32$ to 43$)$ \\
$\begin{array}{l}\text { Small for gestational age birthweight } \\
<10 \text { percentile }\end{array}$ & $1741(3)$ & 119 & 83 & $30(7$ to 47$)$
\end{tabular}

Based on reference [35]. 
enough gestational age, for the remaining duration of the pregnancy, and that can assess both perinatal and maternal outcomes that matter, including not only preterm birth, but also SGA and preterm preeclampsia. Our proposed RCT will address these goals.

\section{The proposed intervention: oral $\mathrm{Mg}^{++}$citrate supplementation in pregnancy}

$\mathrm{Mg}^{++}$citrate is a widely used $\mathrm{Mg}^{++}$supplement: it is inexpensive, easily absorbed and rarely has a detectable laxative effect. It can be taken as a powder, or placed into standard-dose capsules. $\mathrm{Mg}^{++}$citrate has high solubility (55\%) in water, in all states of gastric acid secretion. As demonstrated in one RCT, $\mathrm{Mg}^{++}$citrate appears to be the most bioavailable of all oral $\mathrm{Mg}^{++}$preparations [37]. Thus, oral $\mathrm{Mg}^{++}$citrate is cheap, accessible, easy to manufacture. Thus, a programme of its use in pregnancy in low-middle income countries would be easy to initiate.

\section{Methods/Design \\ Study objectives and design \\ Primary objectives}

i. In women with 1 or more risk factors for an adverse pregnancy outcome, to determine whether there is a reduction in the composite perinatal outcome preterm birth before 37 weeks gestation, stillbirth after 20 weeks gestation, neonatal death before 28 days after birth, or SGA birthweight under the 3rd percentile following the administration of oral $\mathrm{Mg}^{++}$citrate $150 \mathrm{mg}$ twice daily versus oral placebo twice daily.

ii. In women with 1 or more risk factors for an adverse pregnancy outcome, to determine whether there is a reduction in the composite maternal outcome preeclampsia or eclampsia arising before 37 weeks gestation, severe non-proteinuric hypertension arising before 37 weeks gestation, placental abruption, maternal stroke during pregnancy or $\leq 7$ days after delivery, or maternal death during pregnancy or $\leq 7$ days after delivery - following the administration of oral $\mathrm{Mg}^{++}$citrate $150 \mathrm{mg}$ twice daily versus oral placebo twice daily.

\section{Secondary objectives}

i. In women with 1 or more risk factors for an adverse pregnancy outcome, to determine whether there is a reduction in any single component of the composite perinatal outcome - preterm birth before 37 weeks gestation, stillbirth after 20 weeks gestation, neonatal death before 28 days after birth, or SGA birthweight under the 3rd percentile - following the administration of oral $\mathrm{Mg}^{++}$citrate $150 \mathrm{mg}$ twice daily versus oral placebo twice daily. ii. In women with 1 or more risk factors for an adverse pregnancy outcome, to determine whether there is a reduction in any single component of the composite maternal outcome - preeclampsia or eclampsia arising before 37 weeks gestation, severe non-proteinuric hypertension arising before 37 weeks gestation, placental abruption, maternal stroke during pregnancy or $\leq 7$ days after delivery, or maternal death during pregnancy or $\leq 7$ days after delivery - following the administration of oral $\mathrm{Mg}^{++}$citrate $150 \mathrm{mg}$ twice daily versus oral placebo twice daily.

\section{Study design}

We will complete a multicenter double-blind, placebocontrolled randomized superiority clinical trial of oral $\mathrm{Mg}^{++}$citrate supplementation.

\section{Setting}

The study will be done at two major centres: The first centre is the Instituto de Medicina Integral Prof. Fernando Figueira (IMIP), Recife-Pernambuco. IMIP maintains the largest hospital in Brazil exclusively dedicated to SUS. IMIP has 1,032 beds and performs more than 2,000 clinical daily visits. IMIP enrolls about 6,000 deliveries per year and has an obstetric intensive care unit. The second centre is the Dom Malan Hospital (HDM), Petrolina-Pernambuco. HDM assists the population of about 1 million people in 55 municipalities of Pernambuco, Bahia and Piauí States. HDM performs about 600 deliveries per month.

\section{Participant inclusion and exclusion criteria}

The following maternal inclusion criteria must all be met:

- Age 18-45 years at the time of enrollment,

- Gestational age at $12^{1 / 7}$ to $20^{6 / 7}$ weeks,

- Accurate estimated date of confinement, based on the last menstrual period among women with a regular menstrual cycle, or by a first-trimester pregnancy dating ultrasound,

- Singleton pregnancy,

- Current place of residence is within Recife or Petrolina,

- One or more of the following risk factors related to either:

\section{A prior pregnancy}

1. Preterm delivery at $24^{1 / 7}$ to $<36^{6 / 7}$ weeks

2. Stillbirth at $>20^{1 / 7}$ weeks gestation

3. Placental abruption

4. Preeclampsia or eclampsia

5. Liveborn infant with $\mathrm{SGA}<10$ th percentile

6. Liveborn infant with birthweight $<2500$ grams 


\section{The current pregnancy}

1. Nulliparity

2. Chronic hypertension

3. Type 1 or type 2 diabetes mellitus

4. Maternal age $>35$ years

5. Obesity (pre-pregnancy maternal body mass index $\left.>30 \mathrm{~kg} / \mathrm{m}^{2}\right)$

6. Currently smoking cigarettes

Any one of the following constitutes a reason for exclusion from the trial, determined at initial consideration for eligibility:

- Known uncontrolled hyperthyroidism

- Known active parathyroid disease of any kind

- Chronic kidney disease, defined by an estimate glomerular filtration rate under $60 \mathrm{~mL} / \mathrm{min} / 1.73 \mathrm{~m}^{2}$, as determined at baseline entry or by known history

- Chronic diarrheal disease

- High serum $\mathrm{Mg}^{++}$concentration $>9.5 \mathrm{mmol} / \mathrm{dL}$, as determined at baseline entry.

\section{The intervention}

We active arm is $\mathrm{Mg}^{++}$citrate capsules (150 mg elemental $\mathrm{Mg}^{++}$citrate per capsule), and the control arm is matched placebo capsules. Both will be manufactured by IMIP's Department of Pharmacology, and will be identical in colour and shape. The $150 \mathrm{mg}$ twice daily dose was chosen with the aim of achieving daily $\mathrm{Mg}^{++}$needs without causing excess of $\mathrm{Mg}^{++}$circulating levels. The study medication packages will be supplied to each local pharmacy with sequential numbers. Code break envelopes will be supplied to the lead pharmacist, but will be not available for the investigative team. Each pack will be individually prescribed for each participant.

Compliance/adherence, adverse events, and clinical intercurrences will be monitored by the research team at each routine prenatal visit until the completion of the treatment. Adherence will be defined as the ingestion of at least $80 \%$ of the prescribed dose.

\section{Study outcomes}

The individual components of the composite perinatal outcome - preterm birth before 37 weeks gestation, stillbirth after 20 weeks gestation, neonatal death before 28 days after birth, or SGA birthweight under the 3rd percentile - are listed in Table 2. The individual components of the composite maternal outcome - preeclampsia or eclampsia arising before 37 weeks gestation, severe non-proteinuric hypertension arising before 37 weeks gestation, placental abruption, maternal stroke during pregnancy or $\leq 7$ days after delivery, or maternal death during pregnancy or $\leq 7$ days after delivery - are listed in Table 2 .

\section{Randomization scheme}

Participants will be randomized in a 2:1 fashion to either $\mathrm{Mg}^{++}$citrate or placebo. Block randomization will be used to ensure a balanced number of participants in each group at any time during the study.

\section{Data analysis and sample size}

All outcomes will be analyzed by intention to treat (ITT), using logistic regression analysis. The main effects sizes for each outcome will be expressed as a rate $(95 \% \mathrm{CI})$ and odds ratio $(95 \% \mathrm{CI})$.

At the time of study entry, on the day of randomization, all women will undergo a measured serum $\mathrm{Mg}^{++}$and creatine concentration. Any woman whose serum $\mathrm{Mg}^{++}$concentration is over $9.5 \mathrm{mmol} / \mathrm{dL}$, or whose estimated glomerular filtration rate (eGFR is under $60 \mathrm{~mL} / \mathrm{min} /$ $1.73 \mathrm{~m}^{2}$, will be excluded from the trial, and will not be counted in the ITT analysis. Otherwise, all other randomized participants will be included in the ITT analysis regardless of whether they complete the trial.

An efficacy analysis (on-treatment) analysis will be done for each study outcome, wherein women who were adherent with at least $80 \%$ of their dispensed tablets will be analyzed.

At a sample size of 1000 women assigned to placebo and 2000 women assigned to $\mathrm{Mg}^{++}$citrate, with power of $80 \%$ and a 2 -sided P-value of 0.05 , we will be able to detect at least a $22 \%$ relative risk reduction in the primary perinatal composite outcome, assuming a primary perinatal composite outcome rate of $18 \%$ in the placebo group and $14 \%$ in the $\mathrm{Mg}^{++}$group. In Recife there are 25,000 births a year. Of these 25,000, at least $30 \%$ $(7,500)$ would attend one of the study prenatal clinics, \& of those $7,500,60 \%(4,500)$ would meet $\geq 1$ of the eligibility criteria. With a participation rate of $50 \%, 2,250$ women can be recruited in a year, thus requiring 1.25 years to recruit all women, and 2 years ascertain all primary outcome events.

\section{Safety}

The US FDA raised concern about prolonged $\mathrm{Mg}^{++}$ use in pregnancy (http://www.fda.gov/downloads/Drugs/ DrugSafety/UCM353335.pdf). This was prompted by 18 reported cases of fetal and neonatal bone demineralization and fractures following long-term in utero exposure to intravenous over a mean of 9.6 weeks, at a mean total cumulative maternal dose of $3700 \mathrm{~g}$. This adverse outcome was not seen in prior RCTs of 24-48 hour intravenous $\mathrm{Mg}^{++}$sulphate for fetal neuroprotection $(\mathrm{n}=6145$ infants) $[38,39]$ or for the prevention of eclampsia in mothers with preeclampsia $(\mathrm{n}=11,444$ women, including 3283 children followed to 18 months of age) [40]. The latter level I evidence does not negate the risk of prolonged intravenous $\mathrm{Mg}^{++}$to fetal bone development, but the level 
Table 2 Study outcomes, expected results and key indicators

Study outcomes
$\begin{aligned} & \text { 1a. Perinatal composite outcome } \\ & \text { (Main perinatal outcome) }\end{aligned}$
1b. Preterm birth (PTB) (Secondary objective)
1c. Stillbirth (Secondary objective)
1d. Small for gestational age birthweight
$<10$ th percentile (Secondary objective)
1e. Neonatal death < 28 days after birth
(Secondary objective)

1f. Neonatal intensive care unit (NICU) admission (Secondary objective)

\section{2a. Maternal composite outcome} (Main maternal outcome)

2b. Preeclampsia and eclampsia $<37$ weeks gestation (Secondary objective)

2c. Severe non-proteinuric hypertension $<37$ weeks gestation (Secondary objective)

2d. Maternal stroke (Secondary objective)

2d. Maternal intensive care unit (ICU) admission (Secondary objective)

Expected result
Reduction in the rate of the composite perinatal
outcome among infants of women exposed to
outcome among infants of women exposed to $\mathrm{Mg}^{++}$vs. placebo

Reduction in the rate of PTB among infants of women exposed to $\mathrm{Mg}^{++}$vs. placebo

Reduction in the rate of stillbirths among pregnant women exposed to $\mathrm{Mg}^{++}$

Reduction in the rate of SGA among infants of women exposed to $\mathrm{Mg}^{++}$vs. placebo

Reduction in the rate of neonatal death SGA among infants of women exposed to $\mathrm{Mg}^{++}$vs. placebo

Reduction in the rate of NICU admission among infants of women exposed to $\mathrm{Mg}^{++}$vs. placebo

Reduction in the rate of the composite maternal outcome among women exposed to $\mathrm{Mg}^{++}$vs. placebo

Reduction in rate of preterm preeclampsia or eclampsia among pregnant women exposed to $\mathrm{Mg}^{++}$vs. placebo

Reduction in rate of preterm severe non-proteinuric hypertension among pregnant women exposed to $\mathrm{Mg}^{++}$vs. placebo

Reduction in rate of maternal stroke among pregnant women exposed to $\mathrm{Mg}^{++}$vs. placebo

Reduction in the rate of maternal ICU admission among women exposed to $\mathrm{Mg}^{++}$vs. placebo

\section{Key indicator}

Preterm birth $<37$ weeks gestation, stillbirth $>20$ weeks gestation, neonatal death $<28$ days after birth, or SGA birthweight $<10$ percentile

Birth at gestational age $<37$ weeks

Fetal loss after 20 weeks gestation, in the absence of a major congenital anomaly evident at birth

SGA detected by a birthweight $<10$ th percentile

Neonatal death of a liveborn infant from the date of birth up to and including 27 days after birth, in the absence of a major congenital anomaly evident at birth

NICU admission $<28$ days after birth

Preeclampsia or eclampsia $<37$ weeks gestation, severe gestational hypertension $<37$ weeks gestation, placental abruption in pregnancy, or maternal stroke or death during pregnancy or $\leq 7$ days after delivery

Increased blood pressure $>$ 140/90 mm Hg associated with $\geq 2$ proteinuria, and/or seizures, and/or the HELLP Syndrome, arising $<37$ weeks gestation

Increased systolic blood pressure $>160 \mathrm{~mm} \mathrm{Hg}$ or diastolic blood pressure $>105 \mathrm{~mm} \mathrm{Hg}$, with $\leq 1+$ proteinuria, arising $<37$ weeks gestation

Abrupt onset of a focal neurological deficit in the distribution of a brain artery persisting more than 24 hours due to intracerebral hemorrhage or ischemic infarction, arising during pregnancy or $\leq 7$ days after delivery

Adult ICU admission during pregnancy or $\leq 7$ days after delivery
IV data about potential harm are sparse and reflect very high doses of intravenous $\mathrm{Mg}^{++}$sulphate.

At high intravenous doses of $\mathrm{Mg}^{++}$sulphate, maternal side effects (nausea, cutaneous flushing, lassitude and muscle weakness) are common [38-40], essentially bordering between a therapeutic vs. a toxic effect. $\mathrm{Mg}^{++}$ intoxication causes a reduction in serum calcium concentration, leading to rapid decline in maternal serum parathyroid hormone (PTH) concentration - that is, hypocalcaemia may be partly due to the suppressive effects of acute hypermagnesaemia on PTH secretion [41]. Intravenous $\mathrm{Mg}^{++}$sulphate crosses the placental barrier, which may neuroprotective effect the very preterm fetus, including a reduction in the risk of cerebral palsy, without increasing the risk of perinatal death $[40,42]$. While $300 \mathrm{mg}$ of $\mathrm{Mg}^{++}$ citrate contains $12.4 \mathrm{mmol}$ of $\mathrm{Mg}^{++}$, a fair amount is not absorbed, whereas intravenous MgS04 has near-100\% bioavailability. With oral $\mathrm{Mg}^{++}$therapy, the normal serum $\mathrm{Mg}^{++}$level is 0.75 to $0.95 \mathrm{mmol} / \mathrm{L}$. In one $\mathrm{RCT}$ of 4 weeks of supplemental oral $\mathrm{Mg}^{++}$oxalate (400 mg twice daily) in middle-aged non-pregnant adults, serum
$\mathrm{Mg}^{++}$levels only changed from 0.84 to $0.89 \mathrm{mmol} / \mathrm{L}$ [43]. In a second RCT of 16 weeks of $\mathrm{Mg}^{++}$chloride (2500 mg per day) among non-pregnant adults with diabetes mellitus, serum $\mathrm{Mg}^{++}$levels changed from 0.64 to $0.74 \mathrm{mmol} / \mathrm{L}$ [44]. In contrast, among pregnant women who receive intravenous $\mathrm{Mg}^{++}$sulphate - whether as a tocolytic agent in preterm labor, for preeclampsia or for fetal neuroprotection - serum $\mathrm{Mg}^{++}$levels rapidly rise to sustained concentrations of $2.0 \mathrm{mmol} / \mathrm{L}$ or more $[45,46]$. Certainly, acute neonatal depression is positively correlated with maternal serum $\mathrm{Mg}^{++}$concentration in women administered intravenous $\mathrm{Mg}^{++}$sulphate [47]. It is highly unlikely that our proposed dose of $\mathrm{Mg}^{++}$citrate $150 \mathrm{mg}$ twice daily can increase maternal (or fetal) serum $\mathrm{Mg}^{++}$concentration to even $50 \%$ of that seen when intravenous $\mathrm{Mg}^{++}$ sulphate is used in pregnancy.

One of the main determinants of maternal $\mathrm{Mg}^{++}$ handling is renal function, including after oral $\mathrm{Mg}^{++}$administration $[47,48]$. Thus, as a safety measure in our proposed RCT, we will measure maternal serum creatinine concentration at $12-20$ weeks gestation. We will 
deem ineligible any woman whose estimate glomerular filtration rate (eGFR) is under $60 \mathrm{~mL} / \mathrm{min} / 1.73 \mathrm{~m}^{2}$.

In terms of infant safety, we will assess for the presence of hypocalcemia at birth, defined as a total serum calcium concentration in the umbilical cord below $10 \mathrm{mg} / \mathrm{dL}$. These measures will be obtained in all neonates of BRAMAG enrolled mothers who deliver within IMIP and the Dom Malan Hospital. We will also assess for the presence of neonatal osteopenia by plain X-ray examination of all newborns admitted to the neonatal intensive care unit (and who receive a routine chest X-ray as part of their care). It is expected that around $5 \%$ of all newborns studied $(150 / 3,000)$ will have a chest X-ray. Radiological markers of osteopenia will be assessed on these plain radiographs by a radiologist.

\section{Discussion}

We expect that oral $\mathrm{Mg}^{++}$citrate supplements will lower the risk of preterm birth, perinatal mortality and neonatal morbidity, SGA, and will also positively impact on maternal morbidity and mortality. Thus, the intervention might not only save lives, but lower maternal and early childhood disability.

\section{Competing interests}

The authors declare that they have no competing interests.

\section{Authors' contributions}

JGBA: study concept, drafting of manuscript, manuscript revision, approval of final version. JGR: study concept, drafting of manuscript, manuscript revision, approval of final version. CAFLA: study concept, approval of final version. IEAP: study concept, approval of final version. ACG: study concept, approval of final version.

\section{Acknowledgments}

The study is funded by the Brazilian National Council for Scientific and Technological Development (CNPq), the Ministry of Health $(\mathrm{MoH})$ and the Bill \& Melinda Gates Foundation.

Dr. Ray holds a Canadian Institutes for Health Research Chair in Reproductive and Child Health Services and Policy Research.

\section{Adherence to CONSORT guidelines}

The BRAMAG Trial will adhere to the CONSORT guidelines for the reporting of randomized clinical trials.

\section{Author details}

${ }^{1}$ Department of Paediatrics, Instituto Materno Infantil Prof. Fernando Figueira-IMIP, Recife, Brazil. ²Dom Malan Hospital, Petrolina, Brazil. ${ }^{3}$ Departments of Medicine, Obstetrics and Health Policy Management Evaluation, University of Toronto, St. Michael's Hospital, 30 Bond Street, Toronto, ON M5B 1 W8, Canada.

Received: 10 June 2014 Accepted: 4 July 2014

Published: 8 July 2014

\section{References}

1. Preterm birth. http://www.who.int/mediacentre/factsheets/fs363/en/.

2. Rubens CE, Gravett MG, Victora CG, Nunes TM, GAPPS Review Group: Global report on preterm birth and stillbirth (7 of 7): mobilizing resources to accelerate innovative solutions (Global Action Agenda). BMC Pregnancy Childbirth 2010, 10(Suppl 1):S7.

3. Muglia $\sqcup$, Katz M: The enigma of spontaneous preterm birth. N Engl J Med 2010, 362:529-535.
4. Simhan HN, Caritis SN: Prevention of preterm delivery. N Engl J Med 2007, 357:477-487.

5. Romero R, Espinoza J, Kusanovic JP, Gotsch F, Hassan S, Erez O, Chaiworapongsa T, Mazor M: The preterm parturition syndrome. BJOG 2006, 113:17-42.

6. Seubert DE, Huang WM, Wasserman-Hoff R: Medical legal issues in the prevention of prematurity. Clin Perinatol 2007, 34:309-318.

7. Hubinont C, Debieve F: Prevention of preterm labour: 2011 update on tocolysis. J Pregnancy 2011, 2011:941057.

8. Flood K, Malone FD: Prevention of preterm birth. Semin Fetal Neonatal Med 2012, 17:58-63.

9. Estatísticas vitais. http://www2.datasus.gov.br/DATASUS/index.php? area $=0205$.

10. Blencowe $H$, Cousens S, Oestergaard MZ, Chou D, Moller AB, Narwal R, Adler A, Vera Garcia C, Rohde S, Say L, Lawn JE: National, regional, and worldwide estimates of preterm birth rates in the year 2010 with time trends since 1990 for selected countries: a systematic analysis and implications. Lancet 2012, 379:2162-2172.

11. Henderson JJ, MCWilliam OA, Newnham JP, Pennell CE: Maternal factors associated with three phenotypes: spontaneous preterm labour, preterm pre-labour rupture of membranes and medically indicated preterm birth. J Matern Fetal Neonatal Med 2012, 25:642-647.

12. Ananth CV, Getahun D, Peltier MR, Salihu HM, Vintzileos AM: Recurrence of spontaneous versus medically indicated preterm birth. Am J Obstet Gynecol 2006, 195:643-650.

13. Zeitlin J, Ancel PY, Saurel-Cubizolles MJ, Papiernik E: The relationship between intrauterine growth restriction and preterm delivery: an empirical approach using data from a European case-control study. BJOG 2000, 107:750-758.

14. Barros FC, Victora CG, Matijasevich A, Santos IS, Horta BL, Silveira MF, Barros AJ: Preterm births, low birth weight, and intrauterine growth restriction in three birth cohorts in Southern Brazil: 1982, 1993 and 2004. Cad Saude Publica 2008, 24(Suppl 3):S390-\$398.

15. Silveira MF, Victora CG, Barros AJ, Santos IS, Matijasevich A, Barros FC: Determinants of preterm birth: Pelotas, Rio Grande do Sul State, Brazil, 2004 birth cohort. Cad Saude Publica 2010, 26:185-194.

16. Clausson B, Cnattingius S, Axelsson O: Preterm and term births of small for gestational age infants: a population-based study of risk factors among nulliparous women. Br J Obstet Gynaecol 1998, 105:1011-1017.

17. Hershkovitz R, Erez O, Sheiner E, Bashiri A, Furman B, Shoham-Vardi I, Mazor M: Comparison study between induced and spontaneous term and preterm births of small-for-gestational-age neonates. Eur J Obstet Gynecol Reprod Biol 2001, 97:141-146.

18. Kase BA, Carreno CA, Blackell SC, Sibai BM: The impact of medically indicated and spontaneous preterm birth among hypertensive women. Am J Perinatol 2013, 30:843-848.

19. McCowan LM, Bulst RG, North RA, Gamble G: Perinatal morbidity in chronic hypertension. Br J Obstet Gynaecol 1996, 103:123-129.

20. Palo P, Erkkola R: Risk factors and deliveries associated with preterm, severely small for gestational age fetuses. Am J Perinatol 1993, 10:88-91.

21. Groom KM, North RA, Poppe KK, Sadler L, McCowan LM: The association between customised small for gestational age infants and pre-eclampsia or gestational hypertension varies with gestation at delivery. BJOG 2007, 114:478-484.

22. Ray JG, Vermeulen MJ, Schull MJ, Redelmeier DA: Cardiovascular health after maternal placental syndromes (CHAMPS): population-based retrospective cohort study. Lancet 2005, 366:1797-1803.

23. Roberts DJ, Post MD: The placenta in pre-eclampsia and intrauterine growth restriction. J Clin Pathol 2008, 61:1254-1260.

24. Salafia CM, Vogel CA, Vintzileos AM, Bantham KF, Pezzullo J, Silberman L: Placental pathologic findings in preterm birth. Am J Obstet Gynecol 1991, 165:934-938.

25. Ferraz EM, Gray RH: A case-control study of stillbirths in northeast Brazil Int J Gynaecol Obstet 1991, 34:13-19.

26. Bring HS, Varli IA, Kublickas M, Papadogiannakis N, Petersson K: Causes of stillbirth at different gestational ages in singleton pregnancies. Acta Obstet Gynecol Scand 2014, 93:86-92.

27. Salafia CM, Pezzullo JC, López-Zeno JA, Simmens S, Minior VK, Vintzileos AM: Placental pathologic features of preterm preeclampsia. Am J Obstet Gynecol 1995, 173:1097-1105. 
28. Bernal AL: The regulation of uterine relaxation. Semin Cell Dev Biol 2007, 18:340-347.

29. King DE, Mainous AG, Geesey ME, Woolson RF: Dietary magnesium and C-reactive protein levels. J Am Coll Nutr 2005, 24:166-171.

30. Nordic Council of Ministers: Nordic Nutrition Recommendations. Scand J Nutr 1996, 40:161-165.

31. Standing Committee on the Scientific Evaluation of Dietary Reference Intakes, Food and Nutrition Board, Institute of Medicine: Dietary Reference Intakes for Calcium, Phosphorus, Magnesium, Vitamin D, And Fluoride. In National Academies Press. in press.

32. Mittendorf R, Dambrosia J, Dammann O, Pryde PG, Lee KS, Ben-Ami TE, Yousefzadeh D: Association between maternal serum ionized magnesium levels at delivery and neonatal intraventricular hemorrhage. J Pediatr 2002, 140:540-546.

33. Arikan GM, Panzitt T, Gücer F, Scholz HS, Reinisch S, Haas J, Weiss PA: Course of maternal serum magnesium levels in low-risk gestations and in preterm labor and delivery. Fetal Diagn Ther 1999, 14:332-336.

34. Wynn A, Wynn M: Magnesium and other nutrient deficiencies as possible causes of hypertension and low birthweight. Nutr Health 1988, 6:69-88.

35. Makrides M, Crowther CA: Magnesium supplementation in pregnancy. Cochrane Database Syst Rev 2001, 4:CD000937.

36. Harrison V, Fawcus S, Jordaan E: Magnesium supplementation and perinatal hypoxia: outcome of a parallel group randomised trial in pregnancy. BJOG 2007, 114:994-1002

37. Walker AF, Marakis G, Christie S, Byng M: Mg citrate found more bioavailable than other Mg preparations in a randomised, double-blind study. Magnes Res 2003, 16:183-191.

38. Doyle LW, Crowther CA, Middleton P, Marret S, Rouse D: Magnesium sulphate for women at risk of preterm birth for neuroprotection of the fetus. Cochrane Database Syst Rev 2009, 1:CD004661.

39. Costantine MM, Weiner SJ, Eunice Kennedy Shriver National Institute of Child Health and Human Development Maternal-Fetal Medicine Units Network: Effects of antenatal exposure to magnesium sulfate on neuroprotection and mortality in preterm infants: a meta-analysis. Obstet Gynecol 2009, 114:354-364.

40. Duley L, Gülmezoglu AM, Henderson-Smart DJ, Chou D: Magnesium sulphate and other anticonvulsants for women with pre-eclampsia. Cochrane Database Syst Rev 2010, 11:CD000025.

41. Rocha VS, Lavanda I, Nakano EY, Ruano R, Zugaib M, Colli C: Calcium and magnesium status is not impaired in pregnant women. Nutr Res 2012, 32:542-546.

42. Cholst IN, Steinberg SF, Tropper PJ, Fox HE, Segre GV, Bilezikian JP: The influence of hypermagnesemia on serum calcium and parathyroid hormone levels in human subjects. N Engl J Med 1984, 310:1221-1225.

43. Kawano Y, Matsuoka H, Takishita S, Omae T: Effects of magnesium supplementation in hypertensive patients: assessment by office, home, and ambulatory blood pressures. Hypertension 1998, 32:260-265.

44. Rodríguez-Morán M, Guerrero-Romero F: Oral magnesium supplementation improves insulin sensitivity and metabolic control in type 2 diabetic subjects: a randomized double-blind controlled trial. Diabetes Care 2003, 26:1147-1152.

45. Lurie S, Gur D, Sadan O, Glezerman M: Relationship between uterine contractions and serum magnesium levels in patients treated for threatened preterm labour with intravenous magnesium sulphate. J Obstet Gynecol 2004, 24:247-248.

46. Lu JF, Nightingale CH: Magnesium sulfate in eclampsia and pre-eclampsia: pharmacokinetic principles. Clin Pharmacokinet 2000, 38:305-314.

47. Robinson RR, Murdaugh HV Jr, Peschel E: Renal factors responsible for the hypermagnesemia of renal disease. J Lab Clin Med 1959, 53:572-576.

48. Simchen MJ, Dulitzky M, Mashiach S, Friedman SA, Schiff E: Adjustment of magnesium sulfate infusion rate in patients with preterm labor. Am J Obstet Gynecol 1998, 179:994-998.

doi:10.1186/1471-2393-14-222

Cite this article as: Alves et al.: The BRAzil MAGnesium (BRAMAG) trial: a randomized clinical trial of oral magnesium supplementation in pregnancy for the prevention of preterm birth and perinatal and maternal morbidity. BMC Pregnancy and Childbirth 2014 14:222.

\section{Submit your next manuscript to BioMed Central and take full advantage of:}

- Convenient online submission

- Thorough peer review

- No space constraints or color figure charges

- Immediate publication on acceptance

- Inclusion in PubMed, CAS, Scopus and Google Scholar

- Research which is freely available for redistribution

Submit your manuscript at www.biomedcentral.com/submit
C Biomed Central 